\title{
A Related Research between the Piano Education Students' Emotional Development
}

\author{
Ying Qi \\ Shanxi Xueqian Normal University, Xi'an City, Shanxi Province, 710100, \\ China
}

\begin{abstract}
Any art is a true portrayal of human life and vividly manifests human emotions. Piano music is no exception, and it directly demonstrates inner feelings of mankind with specific art symbols and movement forms of sound structure. Therefore, piano teaching activities have a positive effect on the development of students' emotion. Based on the author 's teaching experience, this article first explained the relationship between music and the emotional development and then put forward strategies about how to promote students' emotional development with piano teaching. The results of this paper are conducive to promoting students' all-round development in piano teaching and forming a new piano teaching model.

Keywords: Piano education; Emotion cultivation; Correlation; Development strategies
\end{abstract}

\section{Introduction}

With the development of science and technology and the increasingly intense social competition, how to improve students' overall quality has become the core of education reform. At the same time, people strongly feel the important role that the emotion plays in the comprehensive quality. Emotional education has received full attention in the domestic and international education development[1]. However, many studies have shown that there exists an international and common problem in the study of emotional education - the separation between the theory and practice of emotional education. Reality often 
cannot meet the requirements of the ideal. How to cultivate and develop human emotion has become a major problem in human education. People explore the mystery of emotional development and cultivation from different perspectives and art is one of the hot issues which people concern about. Any art is a true portrayal of human life and vividly manifests human emotions, and so does piano music. It directly demonstrates inner state of mankind with specific art symbols and movement forms of sound structure. Therefore, piano education activities have a positive effect on students' emotional development.

\section{The Relationship Between Music and the Emotional Development}

\subsection{Human emotional life is the performance object of music art}

Any art is a true portrayal of human life and vividly manifests human emotions, and so does piano music. It directly demonstrates inner state of mankind with specific art symbols and movement forms of sound structure. Therefore, human emotional life is the performance object of music art[2]. As human inner psychological culture, a variety of emotional experience generated in human life is rich and diversified, so it determines the colorfulness of the content of music art. For example, some music extols beautiful love in the world, such as the famous violin concerto "Butterfly Lovers"; some music expresses a strong patriotic enthusiasm, such as the song "Songhua River"; some music conveys the praise of nature, such as Mendelssohn's silent song "Spring Song".

\subsection{The form of music is closely correspond to emotional dynamic}

Music is the art of time and it directly prompts and expresses the dynamic form of human emotional life with a variety of music dynamic structures moving along with time. Moreover, the movement of music has some isomorphic relationship with human's mental activity, which is the correspondence between the dynamic structure of emotion and the movement structure of music. Gestalt psychology school believes that all things in the world have a "power schema". The external physical world, the art forms or the internal emotional activities all have a certain force mode of action[3]. Arnheim, a representative scholar of Gestalt psychology, states in Art and Vision, "We must recognize that the force that drives our own emotional activities and the force that acts on the universe are the same force." In his view, it is that the similarity of power schema in the external things and internal emotions may arouse people's aesthetic experience of external things, and make people experience life movement with full of vitality from art works. In the fourth movement of Tchaikovsky's "Pathetique", the sigh in the principal part theme, the descending melody, unstable harmony and staggered string part constitute the emotional "power schema" of "Pathetique" in the music movement. The relationship between melody created by the composer 's creation and his psychological feeling is isomorphic. 


\subsection{The aesthetic process of music is a process to experience emotion fully}

In this process, the appreciator not only grasps the musical dynamic structure of the rhythm, intensity, melody, and harmony, but also participates in their own psychological activities of consciousness, imagination, association and understanding in the appreciation process. In that way, They can fully experience the profound ideological content of music. On one hand, the appreciator strives to fully comprehend the composer's creative thoughts and emotions with his personal experience in this process. On the other hand, the appreciator will connect his personal life experience with the content of the work and freely inject his own emotional experience. If the personal life experience, music cultivation and knowledge is richer and higher, the probability of triggering his emotion in the aesthetic appreciation is greater. Absolutely, his experience is more meticulous[4].

\subsection{The vital emotional expression is the purpose of music performance}

The music performance is not the pale and mechanical sonic movement of the tone. It is to endow life vitality on the lifeless by injecting emotion to trigger deep psychological experience. Therefore, as the second creation of music, music performance should give sound the dynamic structure with life form, so that the performance will be full of emotional meaning. For example, the singer must be good at using a variety of performance skills and personalized self-expression to convey his inner feelings to the audience; a pianist should be with poetic temperament and use various skills to express his emotion with talking sound. This kind of music performance can achieve the purpose of endowing life vitality on the emotional dynamic structure .

\section{Strategies about how to Promote Students' Emotional Development with Piano Teaching}

\subsection{To take the emotional education as one of the objectives in piano teaching}

For a long time, there exists a phenomenon that many teachers often focus on teaching communication technology in piano teaching. Although many students have mastered some playing methods, they do not understand music and do not know how to express and create music. They just play notes rigidly according to the music score when they play music. There is no emotional experience and performance, let alone the association and imagination of the work. This situation has led to that many students take playing piano as as a heavy burden and miserable assignment and they even disgust it. As the expression of human spirit and the carrier of wisdom creation, musical art has always been the advanced form and effective form of human thought communication and emotional expression. To create music is one of the most desirable pattern of manifestation 
of human pursuit of beautiful ideals, sustenance of lofty sentiments, performance of aesthetic taste and aesthetic needs. If students play piano just like a robot to play mechanically, it violates the purpose that music is the expression of emotional will. To this end, we should make the direction of teaching clear[5]. On one hand, we should focus on students' playing skills training; on the other hand, we should further improve students' sense, understanding, imagination and expression of music. Then, we can cultivate their sentiments and purify their minds by music, so that students can improve their music skills, playing techniques, aesthetic consciousness and spiritual realm.

\subsection{To update the teaching content and promote students' emotional development}

First, choose the right materials to enrich and develop students' feelings. In order to achieve a certain playing level as soon as possible, some teachers often allow students to carry out specialized technical training. Therefore, they usually choose more technical training etudes in teaching materials and don't allow students to play songs with rich emotion and different styles. Although students' technical level will continue to improve, the development of students' artistic expression and emotion does not get enhanced. To this end, students should take the necessary technical exercises. On the other hand, teachers should teach works with different themes, genres and styles to enrich and develop students' feelings. By mastering emotions and feelings of works with different themes, genres and styles, we can enrich students' emotional experience and improve their aesthetic quality. Students should be in contact with foreign outstanding works and also should choose some China's piano works. As Chinese descendants, our students receive edification of Chinese local conditions, customs and art at an early age. They have natural sensibility to national music.

Second, choose materials which are easy to understand according to students' characteristics. In piano teaching, many students have mastered some technology well. Some teachers often let students play a few works beyond their understanding in order to enable students to give full play to skills. Although some students can play the work well, it is difficult for them to accurately grasp the emotions of the work. Even if some students can understand the work, it is just a simple experience of the emotion of the music and they cannot understand or master the more profound meaning of the work[6]. For preschool children, college students and even adults, the characteristic of emotional development is from the primary to the advanced and from the simple to the complex. Therefore, students' understanding ability should be taken into account in the choice of materials.

\subsection{To optimize teaching methods and improve teaching efficiency}

(1)To guide students to positively experience the emotion of piano works by appreciation

First of all, we should guide students to get into the situation in teaching, which is to grasp the basic emotions and feelings of the work by throwing yourself into it. 
The so-called "experience" is called "emotional identity" in psychology, which is to experience various emotions contained in works and psychological feelings, mentality and ideology in various situations by imaging yourself into art works. The more emotion invested in the work is, the more feelings are gained and the deeper the understanding of the work is. In piano teaching, we should make students throw themselves into the work with such an experience. For example, teachers can demonstrate the whole work in an accurate, vivid and expressive manner. We should provide them with some high-quality audio and audio information, so that they can directly experience some famous recording to form a higher art world in their minds. This has great significance for them to experience emotions and master the music playing style.

(2) To guide students to understand and comprehend the profound meaning of the work by explanation, conversation, scenarios and other methods

This process is mainly to make students understand and master the ideological content, style and spirit characteristics of the work with rational analysis of the work based on the aesthetic perception. Only when they have a deeper understanding of the emotion and life of this work, may they comprehend the emotional content of music works more profoundly and accurately. Beethoven's work is often referred to as "heroic music"; Chopin's music is called "poetic music"; Tchaikovsky's music is considered as "pathetic music". In order to enable students to accurately grasp the style and spirit of the works, teachers can explain the musician's life and the creative background of the works to students by watching the painting, pictures and audio-visual materials. This will help to create a certain scene to mobilize students' vision and hearing, and trigger their association and imagination[7]. In that way, we can create a truly immersive experience for students.

(3)To allow students to make creative emotional expression with the method that teachers inspire students and students practice repeatedly

The first is to inspire students to make voice expression. In order to express the emotion of works, the playing sound should be rich in expression in the first place, so that students can master the strength of the ups and downs of the sound, recital strumming and specific sound effect played by a variety of touch methods. This will meet the requirement of the style and emotional performances of the work. In addition to using vivid language to inspire students, teachers also can use singing means to appeal students, because singing is the most influential art form and performance means. Teachers can perform the work with the touching tone, natural intonation and mood, coherent melodic lines, long breath and rich emotion together with their students. Besides, teachers can make students sing some parts of the playing work. Using the inner perfect singing to drive the piano playing is an effective method to get good sensibility and expressive force.

The second is to inspire students to play the work with inner feelings. When playing works, students should feel and experience the emotions of the work from the heart and expand their imagination and association wings. In the playing process, the richer the imagination is, the more abundant the feeling is. In teaching, we should inspire students to connect their own psychological 
experience, understanding and comprehension with the form of music and musical movement ways closely. Moreover, we should inspire them to use the inner sense to have a imagination of the emotion, color, detail and the overall layout of the work and form a certain image and picture in the brain.

\section{Conclusion}

Piano education is a kind of emotion reproduction with vitality. At present, the effective use and cultivation of emotions has become the inevitable mission of human education. Therefore, how to cultivate human emotions has become a difficult problem in human education. Piano education is to explore inherent institutional factors of piano education and students' emotional development from the perspective of music. The discussion of the logical relationship between piano education and students 'emotional development in this paper is aimed at analyzing how to integrate the two better to promote the reform of piano education model and the positive development of students' emotion. By means of the analysis of the relationship between the two, we should use targeted attitude and method to promote the integration of piano education and students' emotional development in quality education.

\section{References}

[1] Zeng Huimin. An Analysis of Piano Art Appreciation Class in Colleges and Universities. The Stage, 10, pp.237-238, 2012.

[2] Niu Yi. A Discussion on the Piano Education Method. Journal of Education Institute of Taiyuan University, 04, pp.84-86, 2012.

[3] Wang Xinle. A Research of Aesthetic Education and Emotional Education in Piano Teaching. Beauty and Times, 10, pp.60-61, 2004.

[4] Song Yuqi. An Analysis of Piano Teaching from the Perspective of Emotional Semantics. Popular Literature, 24, pp.250-251, 2013.

[5] Yang Hao. A Discussion of Emotional Penetration of Piano Teaching in Colleges and Universities. The Stage, 05, pp.213-214, 2014.

[6] Wang Jingran. A Discussion of Emotional Penetration of Piano Teaching in Senior High Schools. Music Space, 10, pp.127-128, 2016.

[7] Liu Shui. An Analysis of Emotion Education in Piano Education. Popular Literature, 15, pp.280, 2010. 